\title{
Research on the Teaching and Learning of Traditional Gold and Silver Color Embroidery Technique for Out-of-school Education Taking the Design of Practical Activities of "Inheritance and Innovation of Gold and Silver Color Embroidery" as an Example
}

\author{
Yuwen Zhang \\ Beijing Institute of Fashion Technology, Beijing, 100029, China
}

\begin{abstract}
Gold and silver color embroidery is a process in which gold and silver platinum paper are wound on a silk thread to form gold and silver threads, which are then discarded into various patterns or contour lines, and then colored lines are used to fasten the pattern lines on the base material. Gold and silver color embroidery has a long history as a representative embroidery skill in traditional embroidery techniques. It has complex techniques and deep deposits. Due to the particularity of its materials and techniques, it is faced with many problems in its inheritance in the off-campus education. This paper discusses the problems of the traditional gold and silver color embroidery techniques for off-campus education, the innovation in the process of teaching, the design of practical activities, and their significance, so that traditional skills can promote the national spirit in the new concept and teaching of out-ofschool education, inheriting the human civilization, serving the social harmonious and cultural development, thus achieving the goal of education.
\end{abstract}

Keywords: Gold and silver color embroidery; Out-of-school education; Teaching and learning DOI: http://dx.doi.org/10.26549/jetm.v2i2.730

\section{Historical Origin and Artistic Characteristics of Traditional Gold and Silver Color Embroidery}

\subsection{Historical Origin of Traditional Gold and Silver} Color Embroidery

$\mathrm{G}$ old and silver color embroidery is also called "the gold and silver colored embroidery", which firstly wraps the gold and silver platinum paper around the silk thread to form a gold or silver thread. It is then coiled to various patterns or outlines which are fixed by colored threads on the bottom material. There are two kinds of embroidery threads: "double gold" and "single gold". Generally, "double gold" is more commonly used. It characterizes as the embroidered fabric's being dazzling and gorgeous. ${ }^{[1]}$ In the ancient times, gold and silver color embroidery was also known as "Cujin embroidery", which has a long history, complicated techniques and deep deposits. The earliest object of gold and silver color embroidery was the half-sleeved golden dress of Cujin embroidery of Tang Dynasty, which was excavated in the Famen Temple of Shaanxi. It became quite popular in the Ming and Qing Dynasties, which was mostly used to embroider the golden dragons on emperors' robes and as the court decorations, highlighting the overall beauty and magnificence and demonstrating the honor of wearers.

1.2 Artistic Characteristics of Traditional Gold and Silver Color Embroidery

The pattern subjects of the traditional gold and silver color embroidery include flowers, animals, figures, geom- etry, etc. There are point structure, linear structure, planar structure and integrated structure for composition forms. Although the subjects and composition forms are various, most of the works manifests the connotation that art is above life. From the traditional gold and silver color embroidery works, it can be seen that people have abstracted and idealized the will of praying for good fortune such as the wise men of heaven and earth, moments of beauty, etc. which performs unique prayers in non-verbal ways, expresses the beautiful spiritual sustenance, penetrated with the traditional ideas of China for thousands of years, integrates the traditional culture, customs and regional characteristics as one, and carries a profound cultural connotation.

The material of the traditional gold and silver color embroidery mainly includes two parts: embroidery threads and backing fabrics. Embroidery threads include the main thread i.e. gold and silver threads. The gold threads used by the royal gold and silver are pure gold threads made of hammered gold foil which is twisted; the auxiliary thread is the colored thread used for stitching gold and silver threads, which is mostly silky. The traditional embroidery backing fabrics include satin, silk, cotton and brocade.

The traditional gold and silver color embroidery is rich in color, gorgeous and elegant. In addition to the colors of the main gold and silver threads, the color matching of the auxiliary colored threads is particularly important, including single-color, double-color and multi-color sewing

Corresponding Author: Yuwen Zhang, 45792947@qq.com

Fund Project: This project is supported by the "Special Fund for the Construction of High-Level Teachers of Beijing Institute of Fashion Technology". The project number is: BIFTBJ201807 
threads. Based on the needs of different patterns, the color changes of the colored threads express different structures and textures. The overall color of gold and silver color embroidery also takes into account the clever collocation of other skills of the peripheral area such as seed stitch, plain embroidery, with the color of embroidery backing fabrics.

In terms of the craft and techniques, taking the double gold thread as an example, through the clever combination of stitch techniques and color matching, the two gold threads should be firstly put together in the sewing process and carefully placed along the pattern. Then use colored threads to securely stitch the two gold threads to the patterns. The two gold threads should go spirally in accordance with the continuous changes of the pattern. Due to the different styling characteristics of the decoration positions and patterns, the traditional gold and silver color embroidery presents the differences in appearance and techniques according to the specific decoration requirements, combined with other decoration techniques. For example, the gold and silver color embroidery, which is used for the edge, usually combines with the plain embroidery, applique embroidery and seed stitch; the gold and silver color embroidery, used for the main pattern, is also divided into full-flower filling, embroidery with padding, etc.

In addition, the traditional gold and silver color embroidery presents certain differences in costumes of Han and ethnic minorities. For example, the techniques of gold and silver color embroidery on the costumes of Han, Manchu, Mongol, Miao and Dong nationalities present different artistic characteristics due to the cultural differences.

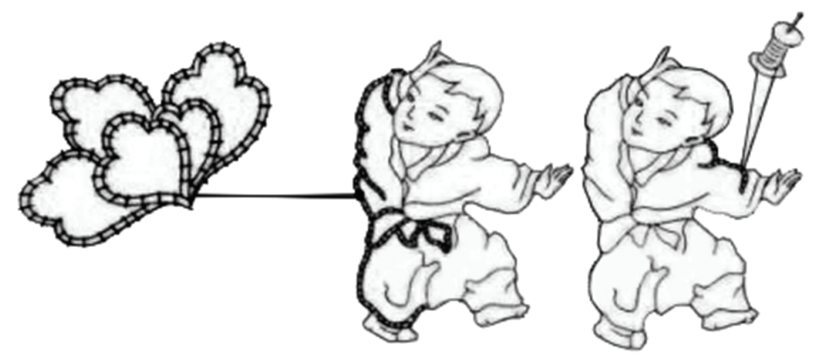

Figure 1. Character outlines coiled by threads ${ }^{[2]}$

\section{Problems that the Teaching and Learning of Traditional Gold and Silver Color Embroidery in Out-of-School Education Faced by}

Out-of-school education is a concept corresponding to out-of-school activities. Some European and American scholars believe that the out-of-school activities are extra curricular activities conducted outside the campus (or on campus, but out of the daily schedule). ${ }^{[3]}$ The content and form of the out-of-school education have more extensibil- ity and flexibility than on-campus education. At the same time, the particularity of the content of out-of-school education makes its implements present greater variability and challenges.

As for the teaching and learning of the traditional gold and silver color embroidery techniques, due to the specialty of the technique itself, such problems will be encountered in the teaching and learning process as the limitations of the traditional materials, the limitations of the length of teaching and learning time, and the difference in technique bases of the learners. The limitations of traditional materials mainly refer to the high cost and scarcity of materials such as gold and silver threads involved in the traditional gold and silver color embroidery technology; besides, the softness of embroidery backing fabrics makes it difficult for beginners to operate; the limitation of the length of teaching and learning time is that the length of time it takes to create the works according to the patterns and techniques of the traditional gold and silver color embroidery is far beyond the length of time used to popularize the basic skills; prior to inheriting the techniques of gold and silver color embroidery, the learners need to have a certain needlework foundation, which, however, is also different. It puts forward higher requirements on the depth of the techniques in teaching and learning.

\section{Innovation of the Teaching and Learning of Traditional Gold and Silver Color Embroidery in Out-of-School Education}

In order to solve the main problems faced by the teaching and learning of the traditional gold and silver color embroidery in out-of-school education, before the teaching activities, it is necessary to conduct in-depth research on the level of the learners' technique base, find proper solutions to the current limitation of materials and length of teaching and learning activities, as well as prepare teaching plans according to the technique characteristics of the traditional gold and silver color embroidery.

\subsection{Follow the "People-Oriented" Education Pur- pose}

In Democracy and Education, Dewey put forward the educational ideas of "school is society", "education is life", "learning from doing", etc. He advocated liberating children's nature, learning from experience, promoting children's personality development. He also believed that education is children's current living process instead of the preparation for future life. "Life is development, while continuous development and growth, may be life. ${ }^{[4]} "$ Select materials that are familiar to learners and suitable for primary production, instead of the materials in traditional gold and silver color embroidery, so as to reduce the cost of teaching and learning, enhance the operability 
of practical activities. The forms of patterns with achievement should be life-oriented. The selection of patterns for teaching and learning should be combined with the learners' ages and the characteristics of the living environment. The induction and innovation of the traditional patterns enable them to create contemporary works adapted to the changes of the new era on the basis of mastering traditional techniques.

\subsection{Create a Situational Learning Model}

The constructivism learning theory considers: knowledge can not exist abstractly from the context of activities. Learning should be combined with the contextualized social practices. ${ }^{[5]}$ The teaching and learning of traditional techniques cannot be separated from the support of the traditional culture, the process of which, is also a process of learning traditional culture. Living in the present, the students still have a certain degree of strangeness to the traditional culture. The creation of a teaching and learning environment, and the analysis of the objects of traditional costumes that are integrated into the teaching and learning activities, help learners to enter their roles, so that they can more deeply appreciate the charm and essence of the traditional culture. At present, many museums do not only provide exhibitions, but also allow visitors to participate in the activities to the greatest extent in accordance with their own needs. A variety of activities vividly illustrate the contents of the exhibitions. Integrating the "real object" gold and silver color embroidery displayed in the museum into the class teaching, it is unmatched by other forms of teaching materials. By organic combination with certain art forms and themes, it is transformed into an intuitive visual education.

\section{Practical Activity Design for the Inheritance and Innovation of Gold and Silver Color Embroidery}

\subsection{Activity Objective}

Make $90 \%$ of the participating middle school students can acquire the basic and entire techniques of gold and silver color embroidery within 8 hours, and can complete embroidery works; students can skillfully use the techniques of gold and silver color embroidery to complete works according to the patterns; students can spontaneously participate in activities, and take exercise to improve their practical ability and psychological endurance.

\subsection{Activity Preparation}

In the aspect of environmental arrangement, teachers shall strive to create an atmosphere of traditional classroom. The teaching preparations shall include the materials sorting of traditional gold and silver color embroidery and the debugging of multimedia teaching facilities; students are supposed to have certain needlework experience before the activity; material preparation items include embroi- dery samples, imitative gold and silver threads, colored threads, embroidery stays, embroidery needles, and embroidery backing fabrics.

\subsection{Activity Process}

\subsubsection{Observation of Ancient Gold and Silver Color Embroidery Works}

Taking the National Costume Museum as the visiting base, the teachers select samples of traditional gold and silver color embroidery displayed in the exhibition hall, explain and analyze it for students, which include the historical background, colors, patterns, the characteristics of gold and silver color embroidery, and the clothing matching of related costumes. The exhibits are from the nationalities of Han, Manchu, Miao and Dong.

4.3.2 Historical Origins, Artistic Characteristics' Analysis and Technique Demonstration of Traditional Gold and Silver Color Embroidery

In the classroom of National Costume Museum, students are taught the historical origin and artistic characteristics of gold and silver color embroidery technique. Select the basic techniques of traditional gold and silver color embroidery to perform detailed process demonstrations.

\subsubsection{Practical Operation of Students}

According to their theoretical knowledge and practical skills, students can select or design patterns according to their own understanding and needlework experience, and use the basic gold and silver color embroidery techniques of the designed patterns to complete the final works.

\subsection{The Desired Effect of Activities}

During the activity, students can acquire the basic theoretical concepts through visiting, presentations, and demonstrations of the content related to knowledge; as for the traditional gold and silver color embroidery techniques, the form of advanced observation about the students in practical operation is mainly used. During the activity, the teachers understand the students' skill levels through ambulant observation. Each student can get one-on-one coaching, and acquire the basic skills of traditional gold and silver color embroidery based on the understanding of knowledge.

\section{The Significance of the Teaching and Learning of Traditional Gold and Silver Color Embroidery in Out-of-School Education}

\subsection{Inherit Traditional Culture and Consolidate Cultural Self-Confidence}

Cultural inheritance is the basic mechanism for a culture to maintain national characteristics, and is also the internal motivation of a culture to maintain the national community. ${ }^{[6]}$ As an outstanding traditional national craftsmanship in China, gold and silver color embroidery is considered as one of the "needlework" crafts handed down from gen- 
eration to generation (hand down from Chinese mothers to daughters), which symbolizes the elders' expectation to the next generation in ingenuity and virtue; it presents the wisdom and the quintessence of the Chinese nation for thousands of years, and also inherits the unique national spirit and folk culture of the Chinese nation. Under the effect of modern production methods, the handicraft production system has been changed, and the traditional gold and silver color embroidery has also been impacted. However, as a product of handcrafts, nowadays its competitiveness in the market is still stronger than those of machine-made. Therefore, it is particularly important to take culture and innovation as the core and use knowledge and technology to generate new values, making gold and silver color embroidery inherit in new inspiration and innovation.

Whether in the East or in the West, it is impossible to separate culture from traditions. Innovation is not the sudden inspiration of any individual artist or designer, but the consequence of knowledge and culture spread and accumulation. ${ }^{[7]}$ Through design changes in aspects such as materials, techniques and patterns, it looks for creative inspiration from traditional techniques and artistic characteristics, works on creative design combined with contemporary lifestyle and aesthetic features, and aims to activate traditional techniques in contemporary clothing and more widely apply traditional craftsmanship under the premise of adapting to the current society. Consequently, it would provide strong support for cultivating high-quality talents, inheriting and innovating culture, and fully serving the society, and contribute to the inheritance and development of traditional culture.

\subsection{Focus on Learners and Promote Personal Growth}

At present, the development of out-of-school education in China has been systematic and large-scale, and is developing toward professionalism. It has realized its own value in trying to solve the problems about family education deficiency, school education shortcoming, and lacking of standardization of social education. Combining with the characteristics of individual learners, it adjusts the contents and methods of the teaching, so as to form the "people-oriented" education model. Outof-school education is a practical classroom. It focuses on the ideology formed by individual life, discusses questions in the context of human development, and emphasizes the uniqueness of extracurricular activities, that is, taking learners at the center and respecting the diversity and differentiation of personal development. It can help to get rid of the shackles of subject knowledge, and allow students to fully understand society, taste and understand life in their learning contents and activities. It combines multiple learning methods to realize students' growth in participation and experience. ${ }^{[8]}$

\subsection{Explore the Diversity and Enlightenment of Out- of-School Education}

For a long time, the educational model of indoctrination has limited the enthusiasm of learners to a large extent, and cannot arouse the interest of learners, especially the young children. The teaching and learning of traditional gold and silver color embroidery technique has been modified according to their own characteristics. The diversity of materials selection, teaching model, and work innovation has been modified to inspire learners to use traditional techniques to create designs adapting to contemporary life. It tries to change the boring mode of education and turn it into a variety of forms of interactive education. Through visits, interactions, hands-on practice, and other forms of learning, it aims to create a learning scenario with a historical value for learners, so that out-of-school education can give full play to the functions. Therefore, it can serves as a supplement to textbooks as well as an extension of textbooks.

It aims to use the traditional technique to promote the national spirit in the practice of new out-of-school education concept as well as teaching and learning, inherit the human civilization, serve the social harmony and cultural development, and achieve the goal of social education. Integrating learners into the tradition by adapting and heuristic education will promote the out-of-school education to bring vitality in the new era.

\section{References}

[1] Shou Shen, Jian Zhang, Xueyi Embroidered Spectrum--Stitchings, Embroidery and Anatomy of Traditonal Hand Embroidery, Chongqing Publishing House, 2010, 71. (in Chinese)

[2] Shou Shen, Jian Zhang, Xueyi Embroidered Spectrum--Stitchings, Embroidery and Anatomy of Traditonal Hand Embroidery, Chongqing Publishing House, 2010, 72. (in Chinese)

[3] [English] D. Rowntree, Jianping Chen et al., A Dictionary of Education, Shanghai Translation Publishing House, 1988, 222. (in Chinese)

[4] J. Dewey, Chengxu Wang, Democracy and Education: An Introduction to the Philosophy of Education, People's Education Press, 1990, 54. (in Chinese)

[5] Zhongliang Feng, Educational Psychology, People's Education Press, 2010, 158. (in Chinese)

[6] Peilan Sun, Embroidery and Apparel Culture[J]. Journal of Silk, 1992(5):44. (in Chinese)

[7] Shilin Zhao, On the Essence of the Inheritance of Ethnic Cultures, Journal of Peking University: Philosophy and Social Sciences Edition, 2002(5):10. (in Chinese)

[8] Liying Kang, Puzzles and Challenges from China's Out-ofschool Education Development, Journal of Beijing Normal University (Social Science Edition), 2011(4):26. (in Chinese) 